\title{
Artigo
}

Resumo

Grito e silêncio: dois ecos que violam a escola esboça falas dos teóricos para subsidiar a análise dos dados da pesquisa. Os mitos do assassinato do pai da horda e da interdição do incesto são vistos como um tempo advindo de uma cultura. Parece que a violência tem um nascedouro no mito e a correnteza se move pelo esgarcamento da pulsão. A educação precisa desejar, é preciso dar sentido à palavra do sujeito, no dizer e no dito, e revelar que a nossa falta é constitutiva, posto que este sujeito é fendido, ao mesmo tempo objeto e causa de desejo. Descritores: escola, violência, grito, silêncio.

\section{GRITO E SILÊNCIO: DOIS ECOS QUE VIOLAM A ESCOLA}

\author{
Maria de Lourdes S. Ornellas
}

Eis sua essência. Num tempo primitivo, os homens viviam no seio de pequenas hordas, cada qual submetida ao poder despótico de um macho que se apropriava das fêmeas. Um dia, os filhos da tribo, rebelando-se contra o pai, puseram fim ao reino da horda selvagem. Num ato de violência coletiva, mataram o pai e comeram seu cadáver. Todavia, depois do seu assassinato, sentiram remorso, renegaram sua má ação e, em seguida, inventaram uma nova ordem social, instaurando simultaneamente a exogamia (ou renúncia) à posse das mulheres do clã do totem e o totemismo, baseado na proibição do assassinato do substituto do pai (O Totem). Totemismo, exogamia, proibição do incesto: Foi esse o modelo comum a todas as religiões, em especial ao monoteísmo. (Roudinesco, 1997, p. 758)

$\AA$

epígrafe acima, refere-se que os mitos do assassinato do pai da horda e da interdição do incesto revelam-se imersos em um tempo advindo de uma cultura. primitiva. Freud (1913/1996a), ao fazer uma distinção entre o fratricídio e o parricídio, postula que o fratricídio é o ato em que os filhos, ao se unirem após matarem o pai, cessaram seu poder abso-

Prof ${ }^{a}$ da Universidade do Estado da Bahia e Psicanalista. 
luto, lutaram para ocupar o lugar e a posição do pai. Para não ocorrer a dizimação total, preservaram as mulheres, por quem haviam realizado o assassinato e marcou a lei contra o fratricídio. Assim, o assassinato do pai desencadeou o ódio pelo ato cometido e o amor pelo laço que unia os filhos, posto que o pai morto passou a ter maior poder e saber do que em vida. Entretanto, é a culpa que fica como o lugar onde amor e ódio se imbricam cem cessar.

Para principiar este artigo o desejo me enredou a fazer uma releitura de Freud, quando escreveu: "Totem e tabu” (1913/1996b), "Leonardo Da Vinci, uma lembrança de sua infância" (1910/1970) e "Moisés e o monoteísmo" (1939/1996c). São escritos que foram criticados por intelectuais da época os quais pontuavam que os referidos textos apresentavam limites. Ainda assim, essas três obrasprimas expressam o agalma ${ }^{1}$, pela veia literária do século XIX e pela inquietação que provocaram no conhecimento científico.

A obra "Totem e tabu" é subdividida em quatro partes: 1) o horror do incesto; 2) o Tabu e a ambivalência dos afetos 3) Animismo, magia e onipotência dos pensamentos; 4) o retorno infantil ao Totemismo. Dessa forma, Freud refere-se nessas quatro partes da obra sobre o incesto, à ambivalência dos afetos, à magia dos pensamentos e ao retorno infantil. É um quarteto que se enoda e se aproxima de "O mal-estar na civilização" (1930/1996c) e merece também uma leitura aprofundada da obra "O futuro de uma ilusão" (1927/1996d).

$\mathrm{Na}$ época, Freud fala de dois desejos recalcados, dois tabus próprios ao Totemismo: o do Incesto e o desejo de matar o pai. Nesse contexto, pode-se afirmar que este é um fenômeno universal, posto que mostra duas interdições, marcos da civilização. Segundo Freud, o Complexo de Édipo é a expressão desses dois desejos, e dessas duas interdições; Vale pontuar que o mito do totemismo tem muita aproximação com o Édipo, este matou o pai e se casou com a própria mãe.

No princípio, Freud pensou que "Totem e tabu" seria um livro inspirado mais nas relações de poder e da política, e nele trabalhou uma teoria da democracia embasada em três necessidades: um ato fundante, a lei e a renúncia ao despotismo. É sabido que "Totem e tabu" não foi tão aceito como um livro político, mas muito contribuiu para a concepção da psicanálise e para o avanço da antropologia, constituindo-se em um estudo que tem relevância para os pesquisadores dessas áreas. Após a releitura de "Totem e tabu", posso indagar: o sujeito é constitutivamente violento, agressivo? 
A agressão está fora e está dentro do sujeito. A agressão é uma força pulsional que pode estar sendo direcionada para fora, o que alguns teóricos nomeiam de heteroagressão, ou, para dentro do sujeito, e que recebe o nome de autoagressão. O dentro e o fora constituem a vida psíquica em busca de se estruturar diante de afetos ambivalentes, como amor e ódio, pulsão de vida e pulsão de morte, e esse manejo de dentro e de fora faz metáfora com a fita de Moebius. ${ }^{2}$

Se a agressão é uma força pulsional, faz-se fundante nesse momento resgatar o termo pulsão. Surgiu na França em 1625, derivado do latim pulsio, para designar o ato de impulsionar. Empregado por Freud (1905/ 1996e) é definido como a carga energética que se encontra na origem da atividade motora do organismo e do funcionamento psíquico inconsciente do homem. A pulsão está relacionada ao psíquico e ao somático e revela quatro características: a carga, que é a essência, o motor da atividade psíquica; a finalidade, que é a satisfação, e pressupõe a eliminação da excitação que se encontra na origem da pulsão; o objeto, que é o meio de atingir a finalidade; e a fonte, processo somático que tem lugar no corpóreo: as zonas erógenas.

Em 1920/1996f, Freud publicou "Além do princípio de prazer", inaugurando um dualismo pulsional: a pulsão de vida e a pulsão de morte. Em 1932, Freud escreve "Novas conferências introdutórias sobre psicaná- 
lise", texto no qual afirma que a pulsão de morte não pode estar descolada da pulsão de vida, ou seja, vida e morte se amalgamam no processo da agressão (Freud, 1932/1996g). Vale resgatar que o neologismo desenvolvido no seminário Mais ainda, Lacan (1972/1996) nomeia o afeto ambivalente de amódio, em outras palavras, uma tentativa de enlaçamento de amor e ódio, afirma, ainda, que o sujeito é estruturado psiquicamente nesse efeito devastador e eufórico. Ao mesmo tempo em que o constructo é ambivalente, ele se engendra na própria ambivalência, e o sujeito tece assim o seu mal-estar na civilização, posto que é sujeito dividido.

Posso dizer que a violência, o que na psicanálise lê-se: agressividade, instinto primário, situado no $e u$ do sujeito, tem um nascedouro no mito, mas a correnteza move-se pelo esgarçamento da pulsão e pela oferta de um modelo identificatório pautado pela violência ou agressividade e pelo gozo imediato. Aulagnier (1979) corrobora, em certa medida, o que venho discutindo até aqui.

Colocará em relevo a importância do projeto identificatório na constituição do Eu e proporá uma identificação que torna evidente as duas faces da violência - força inevitável presente na constituição subjetiva e na organização da cultura, e força aniquiladora e destrutiva dessas possibilidades. (p. 154)

A educação e a sociedade buscam formas de conter essa agressividade e, em geral, tentam canalizar a agressividade do sujeito para atividades artístico-culturais, a produção intelectual e o lazer. Por ser constitutiva do sujeito, a psicanálise diz que a agressividade é controlada pela cultura, pela socialização dos sujeitos e pela lei, e esse conjunto de controles encadeados fomenta a internalização dos controles destrutivos.

Neste momento, é preciso definir para o leitor a diferença entre agressividade e violência. São dois significantes $^{3}$ fundantes, necessários a uma escuta cuidadosa desses dois fenômenos. Para enredar uma leitura sobre a agressividade do sujeito, pergunta-se: a educação está buscando alternativas, de forma manifesta e latente, para falar da violência? Para responder a esta questão, é preciso revelar alguns princípios básicos: como o ato desejado de agressividade, o desejo de violência ganha duas faces, podendo ser voluntário, e relacionado ao campo do consciente, e involuntário, inscrito nas formações do inconsciente.

Costa (1986) afirma que: "podemos entender como violência aquela situação em que o sujeito é submetido a uma coerção e a um desprazer absolutamente desnecessários, ao crescimento, desenvolvimento e manutenção de seu bem-estar, enquanto ser psíquico". (p. 96)

O autor chama a atenção sobre os tipos de violência presentes na contemporaneidade, e acrescenta que, na nossa cultura, costumamos chamar o ato de violento, quando o corpo e a 
pele são marcados para morrer ou mesmo quando o sujeito já faleceu. Não se pode perder de vista que a violência subjetiva, aquela que não se encontra no jornal, na TV, na vitrine, ou seja, a olho nu, é uma violência branca, sutil, que professor $\mathrm{x}$ aluno, e aluno x aluno, cultuam através da indiferença, da ameaça, da reprovação, do silêncio, mas a cada instante pode irromper num grito de socorro.

É aqui que surge a diferença entre agressividade e violência. Precisamente porque já não se trata unicamente dessa agressivização primordial, senão que se trata do estatuto simbólico que rege a condição de ter, o que imediatamente reverte a condição de no seu valor simbólico de reconhecimento. É por isso que os sujeitos passam a se espelhar nos seus objetos. (Jerusalinky, 2004, p. 9)

A fala do autor faz-me pensar o quanto a educação precisa instigar o desejo, ou seja, não deixar que a violência tome conta do espaço da escola. Assim, é preciso que o professor seja instigante nas palavras, no dizer (discurso oral) e no dito (o que se escuta nas entrelinhas deste discurso). O professor ocupa para o aluno o lugar de sujeito suposto saber-SsS ${ }^{4}$; ensinar o aluno que a nossa falta é constitutiva e que nossa incompletude é algo inerente à condição de sujeito da falta, serve para sustentar a escuta e o desejo como atos que precisam encontrar ressonância na escola. Nós, pesquisadores da educação e psicanalistas, somos convocados a observar a escola e a ocupar o lugar desse debate contemporâneo, na tentativa de entender em que medida quando esta escuta do professor ao aluno encontra-se comprometida, ela engendraria o que chamamamos o fenômeno de violência escolar. Por isso, vale a pena resgatar a contribuição de Lacan para a educação, quando trabalhou, em 1948, na XI Conferência dos Psicanalistas da Língua Francesa, a constituição do Eu enquanto origem da agressividade.

Após algum tempo, Lacan (1949/1998) apresenta o artigo sobre o estádio do espelho, marcando uma diferença entre o en epistêmico e o eu subjetivo, e afirmando que o eu ocupa o lugar do imaginário, lugar da constituição do narcisismo e das pulsões primárias e a agressividade marca um exemplo de pulsão primária. O estádio do espelho marca o momento psíquico e ontológico correspondente na criança entre 6 e 18 meses de vida. Nesta fase, a criança percebe sua unidade corpórea, identifica-se com o outro e se enche de júbilo com a descoberta da sua própria imagem.

Após o estádio do espelho, na passagem do eu especular para o eu social é que se revela a cena agressiva na medida em que o 


\section{Artigo}

espelho também lembra o mito de narciso. A princípio, o narcisismo pode parecer ingênuo, mas a agressividade subjacente, expressa neste modus operandi da contemporaneidade, é uma forma de corroborar a violência.

Nesse sentido Sousa (2005), comenta:

Narciso procurou um lugar virgem, terra onde nenhum outro habitante pisara. Embevecido com a própria imagem, não tinha olhos e ouvidos para fora de si. Fosse o mais belo jovem que por ele se apaixonasse, fosse o doce som de eco que o chamasse, nada o desviou do encanto refletido no espelho das águas sedutoras. (p. 81)

Narciso ouve o eco e se enamora da voz e da imagem que vê, imagem que, não sendo ele, não o acolhe não lhe responde. Marcado pela profecia anunciada de seu destino mórbido, eis que, de tanto amar aquela imagem refletida no espelho, desaparece no real do impossível do nó borromeu. $^{5}$

Tomando-se de empréstimo a formulação de Lacan, o Sss, e o levando para a sala de aula, o que acontece é parecido com à relação paciente $\mathrm{x}$ analista. $\mathrm{O}$ que acontece com esse sujeito que sabe (o professor) e com $o$ aluno (que quer saber)? Essa relação professor-aluno está aprisionada no formato da escola: um conjunto de carteiras simétricas, dispostas uma atrás da outra, poucas janelas e uma única porta pela qual entram professor e aluno. Deixar o aluno enfileirado é demonstrar que se tem controle 
sobre os soldadinhos de chumbo que estão à nossa frente; a escassez de janelas pode refletir a preocupação de que uma fenda é suficiente para que o aluno não veja o sol redondo, e não ocorra o risco de fuga.

"Narciso acha feio o que não é espelho" (Veloso, 1968). Nesse sentido, o excesso de narcisismo e/ ou a falta de narcisismo na constituição do sujeito, pode desencadear, atos de agressividade no aluno, mediante à posição que o professor se coloca frente a este aluno. Será que ele é capaz de captar para mais além do seu saber consciente, as falhas na imagem do outro (aluno), a fim de protegê-lo contra os riscos de eventuais passagens ao ato, ou atos de violência? $\mathrm{O}$ sujeito narcisista deforma-se para que o outro o aceite, ou trinca o espelho em busca de negar o que ele lhe apresenta como referência. Esse jogo de presença- ausência é como se fosse ofort$d a^{6}$, faz dele um sujeito tanatizado e entregue a repetições compulsivas. E é aqui onde se encontra o ponto de origem que se manifesta em atos de violência contra o outro.

O narcisismo e o individualismo caminham de mãos dadas; são atos manifestos em nossa cultura e civilização. A lei é consumir objetos que possam vir a suprir as falhas simbólicas por excesso de apelo ao que é da ordem do imaginário, do virtual; seria a economia do funcionamento narcísico primário por excelência: o eu e a sua imagem no espelho. Este é o objeto de consumo por excelência, objeto efeito da captação imaginária, portanto objeto de sedução. A imagem embaça e não podemos ver o líquido que propõe Bauman (2001), quando fala da modernidade, razão por que estamos em busca do objeto perdido. Esse objeto que é sempre perdido, encontra-se evanescente também na escola, e, se quisermos nos aproximar desse objeto, faz-se preciso chegar até a sala de aula. O discurso do professor é único. Apenas o professor ritualiza e autoriza o momento em que o aluno deverá emitir seu semi saber. O olhar severo é uma tática de dominação, o silêncio às vezes fala mais que as palavras, e, nesse olhar silencioso, o professor determina o que será feito.

A violência na escola, ora é velada, ora é exposta, ela denuncia e incomoda o seu entorno. Há no sujeito a necessidade de fazer-se $U m$ sob pena de não ser Nada, o que tem relação com o narcisismo como um Bem último. Postula o pesquisador que o "primeiro objeto é fundamentalmente rival no sentido narcisista, o mais primitivo; ele impõe a lei do ou ele, ou eu. É a vida mesmo que está em questão aqui e não ainda o amor". (Bergeret, 1995, p. 222)

Faz-se necessário aprofundar o que constitui a violência fundamental, que revela a violência pulsional e civilizatória, levando-se em conta as violências subjetiva e social. escutar a violência em sua constitutividade humana não significa assumir o lugar de permissividade pelos atos de violên- 
cia praticados. faz-se necessário que a escola acolha as relações que se organizam no lócus escolar, os restos de violência deixados na sala de aula, nos corredores, aqueles que as câmeras registram; os passos andados e, no portão de entrada, quando um suspiro de alívio anuncia o que fez falta e aquilo que o outro fez faltar.

Caso o professor tenha desejo de que seu aluno se torne sujeito, ele precisa incluir no seu planejamento que é preciso ousar sair da ordem simétrica do saber cartesiano, provocar a dialética do saber, e mostrar que a relação com o outro é marcada pela incompletude. A partir de nossa reeleitura de "Totem e tabu" fica inscrito que o que estrutura a civilização não é só o assassinato do pai, mas a reação dos irmãos frente ao crime. A análise que engendro, neste escrito, à partir do conceito de Totemismo é que após o Assassinato do Pai, a Lei da Interdição do Incesto se inscreve no lugar do seu desejo, determinando uma nova economia de gozo. É o que chamamos de Metáfora Paterna, o desejo do Pai tirânico, não é mais a lei que rege a vida do clã. mas, a Lei da Interdição do Incesto, que se inscreve como substituta do Pai Morto. Este, que outrora fora odiado, passa a ser idealizado pelos filhos, gerando as disputas imaginárias fratricidas. A referência simbólica ao pai morto, enquanto ausente, determina uma economia de gozo onde os filhos não mais se disputam em rivalidade a este Pai, que encarna pelo seu desejo onipotente, a própria lei. A fratria se organiza em referência à Lei Paterna que se inscreve enquanto função simbólica. $\mathrm{Na}$ contemporaneidade face ao declíno da função paterna, abre-se espaço para as disputas imaginárias, muitas vezes, desencadeadoras do que chamamos violência ou passagem ao ato.

É possível pensar que a violência fundamental funda, enquanto princípio, que foi necessário matar o pai, velar sua morte, assumir a orfandade, para que os filhos pudessem organizar as leis de diferenças e semelhanças. Nesse sentido, a autora a seguir contribui com uma indagação pertinente:

Quando existem promessas de uma sociedade que satisfaria plenamente as necessidades preenchendo todas as faltas e saberes, não seria mais difícil "matar o pai?" Sabemos, entretanto que essas promessas se fazem à custa de sedução, submissão ao poder pela demanda de amor, jogos perversos, apatia, preconceitos com tudo o que for diferente. (Marin, 2006, p. 45)

Ao escrever esta citação, emerge uma inquietação: será que os sujeitos em certa medida não desejam essa sociedade feliz, que nada 
falte, sem necessariamente matar o pai tirânico, apostando muito mais nas promessas contidas nos livros de autoajuda e naquelas engessadas nos palanques eleitorais?

Prefiro continuar pensando, e quem sabe troco a repetição por um ato de criação. Parece-me que a educação precisa contribuir com esta inquietação e deve tentar o exercício que a relação que acontece no interior da escola seja pautada na questão do sujeito divido, sujeito do desejo, da falta.

É preciso analisar o lugar e a posição que a escola ocupa na formação dos sujeitos, com relação ao manejo da violência, seja pela classe social, etnia, avaliação, hostilidade, doença, delinquência, loucura, disciplina etc.

Sabe-se que a disciplina ordena a violência e nesse enfoque Foucault (1977, citado por Marin, 2006) expressa uma contribuição singular a essa questão: "Encontra-se uma forma de ajustar a multiplicidade dos homens por meio da docilização, das especializações, da divisão do conhecimento e do ordenamento, mascarando muitas vezes as práticas da violência que eram claras quando se restringiam aos castigos corporais etc." (Marin, 2006, p. 51).

As leituras que venho fazendo sobre psicanálise e educação me fazem pensar que a psicanálise está conectada à questão da violência na escola, pensando e estudando alternativas para escutar os professores, alunos e pais. Penso que se faz necessário ini- 
cialmente tomar o assento da escola e conversar com o professor, uma escuta analítica, que coloque seu desejo, limites, possibilidades, mas essencialmente a escuta do que fala, como fala e onde sua fala claudica.

Nesse sentido, Marin (2006) é novamente convidada para contribuir no debate sobre o lugar do professor. Pergunta ela: "como sustentar esse lugar? Deixando-se destruir, devorar, canibalizar; única forma, como aponta a Psicanálise, de como o sujeito pode aprender" (p. 52).

Vale pontuar que este não é um lugar fácil de ser ocupado, mas o sentido dessa escritura é que o professor é convidado a cavar as fundações, principiar o alicerce, arrumar os "tijolos por tijolos num desenho mágico, lógico", até se aproximar da "cumeeira". É nesse instante insustentável que ele morre ou se mata.

Matar o mestre para se tornar o mestre de si mesmo, esta é uma lição que, já vimos, pode ser extraída até mesmo da vida de Freud. Talvez não se possa imaginar uma pedagogia organizada em torno de um princípio como esse, o do "assassinato". Mas um educador esclarecido verá nessa idéia uma espécie de referência, que, se bem analisada e compreendida, pode ser até mesmo libertadora. (Kupfer, 2001, p. 99)

Pretendo agora fazer um ponto, mas que não é final. Talvez um ponto de continuidade, pois desejo convidar o professor a assumir o papel de canibal, comer a si mesmo, ao seu sabor e saber e, em seguida, pedir a sobremesa.

SCREAM AND SILENCE: TWO ECHOES VIOLATING THE SCHOOL

\section{Abstract}

Scream and Silence: two echoes that violate the school outlines the theoretical lines to belp analyze the survey data. The myths of the murder of the father of the horde and the probibition of incest seen as a time coming from a culture. It seems that violence has a birthplace in the myth and the current moves by the fraying of the drive. Education must desire you need to give meaning to the word of the subject, and told in the words, and reveal that our lack is constitutive, since this subject is split, while object and cause of desire.

Index terms: School violence, scream, silence. 


\section{GRITO Y SILENCIO: DOS ECOS QUE VIOLAN LA ESCUELA}

\section{Resumen}

Grito y silencio: dos ecos que violan la escuela bosqueja bablar de los teóricos para subsidiar el análisis de los datos de la investigación. El mito del asesinato del padre de la borda y de la probibición del incesto se considera como una época sucedió de una cultura. Parece que la violencia tiene un lugar de nacimiento en el mito y los rapids si los movimientos para raerse del pulsão. La educación necesaria a desear, es necesaria dar sensible la palabra del ciudadano, en decir y en dicho y divulgar que nuestra carencia es constitutiva, alinee que este ciudadano es fendado $y$ al mismo tiempo es causa del deseo del objeto.

Palabras clave: escuela, violencia, grito silencio.

\section{REFERENNCIAS}

Aulagnier, P. A. (1979). A violência da interpretação. Rio de Janeiro: Imago.

Bauman, Z. (2001). Modernidade líquida. (P. Dentzien, trad.) Rio de Janeiro: Jorge Zahar.

Bergeret, J. (1995). La violence fondamentale. Paris: Dunod.

Costa, J. F. (1986). Violência e psicanálise. Rio de Janeiro: Graal.

Foucault, M. (1977). Vigiar e punir. Rio de Janeiro: Vozes.

Freud, S. (1970). Leonardo da Vinci e uma lembrança de sua infância. In S. Freud, Edição standard brasileira das obras psicológicas completas de Sigmund Freud (J. Salomão, trad., Vol. 11, pp. 53-124). Rio de Janeiro: Imago. (Trabalho original publicado em 1910)

Freud, S. (1996a). Totem e tabu. In S. Freud, Edição standard brasileira das obras psicológicas completas de Sigmund Freud (J. Salomão, trad., Vol. 13, pp. 11-162). Rio de Janeiro: Imago. (Trabalho original publicado em 1913)

Freud, S. (1996b). Moisés e o monoteísmo. In S. Freud, Edição standard brasileira das obras psicologicas completas de Sigmund Freud (J. Salomão, trad., Vol. 23, pp. 13-67). Rio de Janeiro: Imago. (Trabalho original publicado em 1939)

Freud, S. (1996c). O mal-estar na civilização. In S. Freud, Edição standard brasileira das obras psicológicas completas de Sigmund Freud (J. Salomão, trad., Vol. 21, pp. 81-117). Rio de Janeiro: Imago (Trabalho original publicado em 1930)

Freud, S. (1996d). O futuro de uma ilusão. In S. Freud, Edição standard brasileira das obras psicológicas completas de Sigmund Freud (J. Salomão, trad., Vol. 21, pp. 15-66). Rio de Janeiro: Imago. (Trabalho original publicado em 1927)

Freud, S. (1996e). Três ensaios sobre a teoria da sexualidade. In S. Freud, Edição standard brasileira das obras psicológicas completas de Sigmund Freud (J. Salomão, trad., Vol. 7, pp. 120-219). Rio de Janeiro: Imago. (Trabalho original publicado em 1905)

Freud, S. (1996f). Além do princípio de prazer. In S. Freud, Edição standard brasileira das obras psicológicas completas de Sigmund Freud (J. Salomão, trad., Vol. 18, pp. 1385). Rio de Janeiro: Imago. (Trabalho original publicado em 1920)

Freud, S. (1996g). Novas conferências introdutórias sobre psicanálise. Conferência XXXIV: Explicações, aplicações e orientações. In S. Freud, Edição standard brasileira das obras psicológicas completas de Sigmund Freud (J. Salomão, trad., Vol., pp. 135-154). Rio de Janeiro: Imago. (Trabalho original publicado em 1932)

Jerusalinsky, A. (2004). Somos todos violentos? Revista da Associação Psicanalitica de Porto Alegre, 7(12), 6-12.

Kupfer, M. C. M. (2001). Freud e a educaşão: o mestre do impossivel. São Paulo: Scipione.

Lacan, J. (1996). O seminário, livro 20: mais ainda. Rio de Janeiro: Jorge Zahar. (Trabalho original publicado em 1972)

Lacan, J. (1998). O estádio do espelho como formador da função do eu. In J. Lacan, Escritos (V. Ribeiro trad., pp. 96-103). Rio de Janeiro: Jorge Zahar. (Trabalho original publicado em 1949) 
Marin, (2006). O não violento. Estilos da Clínica. Revista sobre a Infância com Problemas, 11(20), 38-57.

Roudinesco, E. (1997). Dicionário de psicanálise. Rio de Janeiro: Jorge Zahar.

Sousa, M. (2005). Violência: uma abordagem psicanalítica. Rio de Janeiro: Companhia das Letras.

Veloso, C. (1968). Sampa. São Paulo. [CD Musical]

\section{NOTAS}

1 Agalma: Objeto de desejo, brilhante, galante, termo que vem do Gal, brilho, no antigo francês. J. Lacan utiliza esta expressão no Seminário 8 - A Transferência (1993, p. 139).

2 Fita de Moebius: Uma fita de Moebius é um espaço topológico obtido pela colagem das duas extremidades de uma fita, após efetuar mais-volta numa delas. Deve o seu nome a August Ferdinand Moebius, que a estudou em 1838. Lacan fez uma releitura dessa fita e a utilizou para falar do dentro e do fora na relação com o inconsciente.

3 Significantes: Em psicanálise, significante transformou-se no elemento fundante do discurso que determina os atos, as palavras e o destino do sujeito, à sua revelia e à maneira de uma nomeação simbólica. (Roudinesco, 1997 p. 708)

4 Sss: Lacan utiliza essa nomeação para explicar que o sujeito atribui um saber ao analista. Um respeito ao saber do seu gozo: um saber que o sujeito acredita necessitar para superar seus problemas. (ver Lacan, seminário 11)

5 Nó borromeu: Lacan utilizou esse conceito em 1953, constituído do real, simbólico e imaginário. São três elos enodados de tal forma que, se um se rompe, os demais se soltam. O nome borromeu espelhou-se no brasão das famílias borromeas da Itália. Conclui seu Seminário RSI dizendo que o sujeito é estruturado nessa tríade.

6 Fort-da: Par simbólico que simboliza presença x ausência, que Freud utilizou com uma criança de 18 meses, para explicar a noção do princípio do prazer e do princípio da linguagem.

7 Objeto pequeno a: Termo introduzido por Lacan para designar, se por um lado, o objeto pequeno a é o objeto desejado pelo sujeito e tem a concepção também de ser causa de desejo, por outro, no final da análise, o analista cai, para deixar que o sujeito advenha no seu agalma.

ornellas1@terra.com.br 